\title{
Enfermedades profesionales en la industria del cobre: extracción, manufactura y reciclaje
}

\author{
Occupational diseases in copper industry: extraction, manufacturing and \\ recycling
}

\section{Cabrera-Marutz, CD.' Velásquez-Alcalá, S. ${ }^{2}$ Vrhovac-Biljesko, J.'}

1. Unidad Docente de Medicina del Trabajo de la Comunidad de Madrid, Hospital Universitario 12 de Octubre. Madrid. España.

2. Unidad Docente de Medicina del Trabajo de la Comunidad de Madrid, Hospital Universitario La Paz. Madrid. España.

Recibido: 23-01-14

Aceptado: 17-07-14

\section{Correspondencia}

Carlos D. Cabrera Marutz

Médico Especialista en Medicina Familiar y Comunitaria

Residente Medicina del Trabajo

Servicio de Prevención de Riesgos Laborales

Hospital Universitario 12 de Octubre

Avda. de Córdoba, s/n

28041 Madrid. España.

Teléfono: 910221081

Correo electrónico: energeticoscys@gmail.com

\section{Resumen}

Introducción: El cobre por sus características se utiliza en una gran variedad de aplicaciones en la industria energética, sus múltiples usos unidos a la expansión y evolución de los diversos sectores industriales lo hacen una pieza fundamental para lograr el desarrollo sostenible de la sociedad actual. La minería, procesamiento, reciclaje y su transformación genera riqueza, crea puestos de trabajo y a su vez puede suponer un riesgo potencial para el desarrollo de enfermedades profesionales.

Objetivo: Realizar una revisión bibliográfica que permita identificar las principales enfermedades profesionales que desarrollan los trabajadores de la industria de cobre.

Metodología: Se realizó búsqueda bibliográfica en las siguientes bases de datos: MEDLINE (PUBMED), OSH UPDATE, IBECS, LILACS. Se revisó la literatura científica en busca de posibles enfermedades profesionales en la industria del cobre.

Resultados: Se incluyeron en el estudio un total de 16 artículos científicos que cumplían los criterios de inclusión, agrupándolos en 4 categorías: cáncer de pulmón y vías respiratorias 10; 6 describían enfermedades respiratorias crónicas (neumoconiosis, EPOC); 5 se referían a otros tipos de cánceres (urotelial, Linfoma No Hodking, de estómago, de vejiga, de colon, de hueso, de hígado) y 2 reportaron alergias de contacto.

Conclusiones: Las principales enfermedades detectadas en los trabajadores de la industria del cobre fueron cáncer de pulmón y vías respiratorias y en segundo lugar enfermedades respiratorias crónicas. La 
minería fue el sector más afectado. Existe escasa literatura científica que identifique la aparición de enfermedades profesionales relacionadas con el reciclaje de cobre.

Med Segur Trab (Internet) 2014; 60 (237) 756-778

Palabras Clave: Cobre; Minería; Enfermedades Profesionales; Reciclaje; Manufactura; Fundición.

Abstract

Introduction: Due to its characteristics, copper is used in a variety of applications in the energy industry. Its many uses, along with the expansion and evolution of the various industrial sectors, constitute it a vital piece for the sustainable development of the society. The mining industry, the mining process, recycling and its transformation generates wealth, creates jobs and in turn it may mean a potential risk for the development of occupational diseases.

Objective: To do a literature review to identify the main diseases related to copper industry.

Methodology: A literature search was conducted in the following databases: MEDLINE (PUBMED), OSH UPDATE, IBECS and LILACS. Scientific literature was reviewed for possible occupational diseases in the copper industry.

Results: A total of 16 scientific articles meeting the inclusion criteria were included in the study, we grouped them into 4 categories: lung cancer and respiratory tract diseases-10 articles; 6 articles describing chronic respiratory diseases (pneumoconiosis, COPD); 5 articles related to other types of cancers (urothelial cancers, non-Hodgkin lymphoma, stomach, bladder, colon, bone and liver) and 2 articles reporting contact allergies.

Conclusions: The main diseases among industrial workers were lung cancer and respiratory system diseases. On the second place were chronic respiratory diseases. Mining was the most affected sector. There is a poor scientific literature which identifies the occurrence of occupational diseases related to copper recycling.

Med Segur Trab (Internet) 2014; 60 (237) 756-778

Keywords: Copper; mining; occupational diseases; recycling; manufacturing; foundry. 


\section{INTRODUCCIÓN}

El cobre por sus características se utiliza en una gran variedad de aplicaciones en la industria energética, sus múltiples usos unidos a la expansión y evolución de los diversos sectores industriales lo hacen una pieza fundamental para lograr el desarrollo sostenible de la sociedad actual. La minería, procesamiento, reciclaje y su transformación genera riqueza, crea puestos de trabajo y a su vez puede suponer un riesgo potencial para el desarrollo de enfermedades profesionales.

El cobre es un elemento metálico maleable y dúctil que es un excelente conductor de calor y electricidad, además de ser resistente a la corrosión y antimicrobiano. El cobre se produce de forma natural en la corteza terrestre en una variedad de formas. Puede ser encontrado en depósitos de sulfuros (como calcopirita, bornita, calcocita, covelita), en los depósitos de carbonato (como la azurita y malaquita), en los depósitos de silicatos (como chrysycolla y dioptase) y cobre puro «nativo» ${ }^{1}$.

El cobre también se halla naturalmente en los seres humanos, animales y plantas. Todas las formas de vida orgánica se han desarrollado en un entorno que contiene cobre. Como un nutriente y un elemento esencial, el cobre es vital para mantener la salud ya que algunas funciones de mantenimiento de la vida dependen de cobre.

El cobre es uno de los metales más reciclado. Su alta reciclabilidad lo hace ser un material de elección. Cobre reciclado (también conocido como cobre secundario) no se puede distinguir de cobre primario (cobre originario a partir de minerales), una vez reprocesado. Con el reciclaje de cobre se extiende la eficiencia del uso del metal, se traduce en un ahorro de energía y contribuye a asegurar que tenemos una fuente sostenible de metales para las futuras generaciones.

La demanda de cobre seguirá siendo conocida por el descubrimiento de nuevos yacimientos, las mejoras tecnológicas, diseño eficiente, y el aprovechamiento de la reutilización y el reciclaje. Además, la competencia entre los materiales, y la oferta y la demanda de principio, contribuyen a garantizar que los materiales se utilizan de manera eficiente y eficaz.

El cobre es un importante contribuyente a la economía nacional de los países desarrollados y en vías de desarrollo. La minería, el procesamiento, el reciclaje y la transformación de metal en una multitud de productos, crea puestos de trabajo y genera riqueza. Estas actividades contribuyen a la construcción y mantenimiento de la infraestructura de un país, y crean oportunidades de comercio e inversión. El Cobre seguirá contribuyendo al desarrollo de la sociedad en el futuro haciendo contribuciones vitales a mantener y mejorar la sociedad.

Las características químicas del cobre, las propiedades físicas y estéticas lo convierten en un material de elección en una amplia gama de aplicaciones de la tecnología doméstica, industrial en general, electrónica, etc.

Aleado con otros metales, tales como zinc (para formar latón), de aluminio o de estaño (para formar bronces), o níquel, por ejemplo, se pueden adquirir nuevas características para su uso en aplicaciones altamente especializadas. Los beneficios del cobre se extienden más allá de las características mecánicas:

- El cobre es esencial para la salud de las plantas, los animales y los seres humanos. Las deficiencias, así como los excesos, pueden ser perjudiciales para la salud.

- Propiedades antimicrobianas: Debido a las propiedades antimicrobianas del cobre, éste y sus aleaciones pueden ser utilizados para eliminar agentes patógenos y reducir la propagación de enfermedades.

- Reciclaje: El cobre es uno de los metales más reciclado. Prácticamente todos los productos a base de cobre pueden ser reciclados y el cobre reciclado no pierde ninguna de sus propiedades químicas o físicas. 
- Eficiencia Energética: El cobre puede mejorar la eficiencia de los sistemas de producción y distribución de energía.

La demanda mundial de cobre sigue creciendo; su uso en el mundo refinado se ha más que triplicado en los últimos años gracias a la expansión de sectores como el de los productos eléctricos y electrónicos, la construcción de edificios, maquinaria y equipo industrial, equipo de transporte, y productos en general. Algunos de los aspectos más destacados de la producción y el uso del cobre se enumeran a continuación (Tabla 1):

\begin{tabular}{ll}
\hline INDUSTRIA ELÉCTRICA & Sistemas eléctricos: cables, generadores, motores, transformadores \\
\hline ENERGÍA RENOVABLE & Eólica, geotérmica, paneles solares \\
\hline INDUSTRIA ELECTRÓNICA & Dispositivos electrónicos, sistemas de transmisión de datos, ADSL, \\
Y TELECOMUNICACIONES & HDSL, internet, telefonía, microprocesadores \\
\hline INDUSTRIA DE LA & $\begin{array}{l}\text { Plomería, grifos, válvulas, fachadas, toldos, puertas, marcos de } \\
\text { ventana, rociadores de incendios, techos etc. }\end{array}$ \\
CONSTRUCCIÓN & $\begin{array}{l}\text { Barcos, buques, automóviles, vehículos eléctricos e híbridos, } \\
\text { aviones, trenes }\end{array}$ \\
\hline INDUSTRIA DEL TRANSPORTE & Engranajes, cojinetes y alambres de turbina \\
\hline MAQUINARIA Y EQUIPO & \\
\hline INDUSTRIAL &
\end{tabular}

La Enfermedad Profesional se define médicamente como el daño, la patología médica o traumática provocada por la presencia en el medio ambiente laboral de factores o agentes físicos, químicos o biológicos que merman la salud del trabajador. En España está definida en el Art. 116 de la Ley General de Seguridad Social: "la contraída a consecuencia del trabajo ejecutado por cuenta ajena en las actividades que se especifiquen en el cuadro que se apruebe por las disposiciones de aplicación y desarrollo de esta Ley, y que esta proceda por la acción de elementos o sustancias que en dicho cuadro se indiquen para cada enfermedad profesional». Esta definición sigue siendo válida para contar las enfermedades profesionales, pero con la aprobación de la Ley 20/2007 los trabajadores autónomos (no trabajan por cuenta ajena) si tienen derecho a las prestaciones por contingencia profesionales, en el caso de los autónomos económicamente dependientes es obligatoria la cotización y por tanto la prestación y para el resto de los autónomos esta cotización es voluntaria ${ }^{2}$.

\section{PRODUCCIÓN MUNDIAL 1}

Las cifras preliminares indican que la producción minera mundial de cobre en el 2012 llegó a 16,7 millones de toneladas. El mayor productor de cobre de mina fue Chile (más de 5,4 millones de toneladas). Producción de fundición en 2012 alcanzó alrededor de 16,7 millones de toneladas. China fue el mayor productor de blíster y ánodos en 2012 (más de 5,3 millones de toneladas). Producción de Refinería en 2012 aumentó a 20,1 millones de toneladas, incluidos 3,6 millones de toneladas de la producción refinada secundaria $^{3}$ (Figura 1). 
Figura 1. Producción minera mundial de Cobre

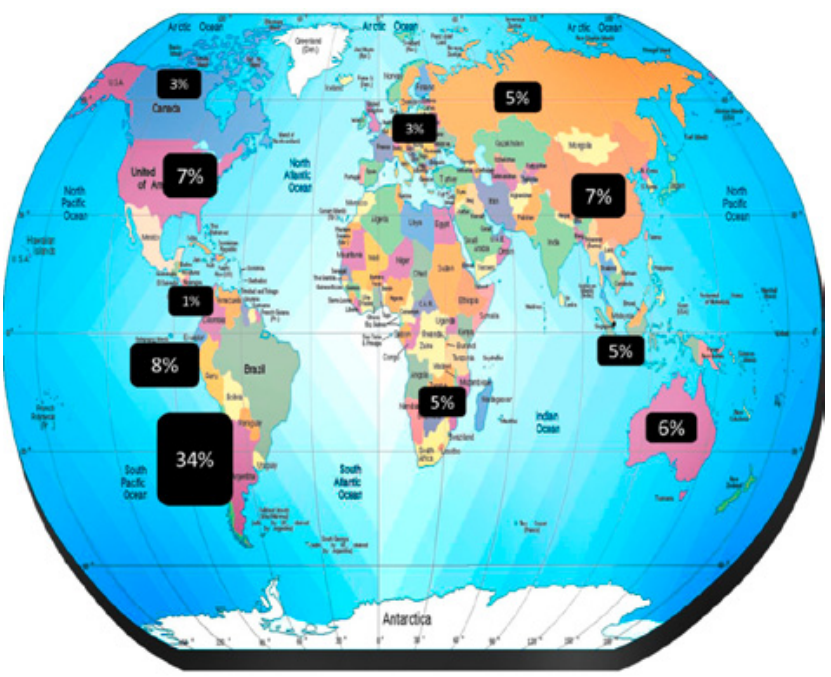

\section{INDUSTRIA DE PRODUCCIÓN Y MANUFACTURA}

La producción primaria de cobre comienza con la extracción de minerales que contienen cobre. Hay tres formas básicas de la minería del cobre: de superficie, la minería subterránea y lixiviación. La minería a cielo abierto es el método de explotación predominante en el mundo.

\section{INDUSTRIA DEL RECICLADO}

El cobre es uno de los pocos materiales que no se degradan o pierden sus propiedades químicas o físicas en el proceso de reciclaje. Teniendo en cuenta esto, el depósito de cobre existente en uso, se puede considerar una parte legítima de las reservas mundiales de cobre. Si se maneja adecuadamente, el reciclaje tiene el potencial de extender el uso de los recursos, y reducir al mínimo el uso de energía, algunas emisiones, y la eliminación de residuos. En 2011, el ICSG ${ }^{3}$ estimó que más del $30 \%$ del consumo de cobre proviene de cobre reciclado. Los requerimientos de cobre de algunos países dependen en gran medida de cobre reciclado para satisfacer las demandas internas. Sin embargo, el cobre reciclado por sí solo no puede satisfacer las necesidades de la sociedad, por lo que también nos basamos en el cobre producido a partir del tratamiento de los minerales.

\section{PATOLOGÍAS DERIVADAS DEL USO DEL COBRE Y SUS ALEACIONES}

La industria del cobre al ser tan amplia, abarca una gran cantidad de patologías que se asocian a la exposición laboral de los trabajadores que desempeñan sus funciones en este sector. Solo un pequeño porcentaje de estas patologías han sido consideradas como enfermedad profesional, entendiendo por esta según el acuerdo con el Protocolo de 2002 del Convenio sobre seguridad y salud de los trabajadores, 1981 de la OIT, como toda enfermedad contraída por la exposición a factores de riesgo que resulte de la actividad laboral ${ }^{4}$.

En la industria de la minería interesa destacar la mayor incidencia del cáncer del pulmón así como las neumoconiosis, que son las enfermedades causadas por la inhalación del polvo inorgánico, dentro de las que se incluyen':

- Silicosis.

- Neumoconiosis por metales.

- Neumoconiosis del trabajador del carbón. 
- Asbestosis.

- Silicatosis.

La Silicosis es una enfermedad pulmonar fibronodular difusa causada por Sílice Cristalino [Dióxido de Silicio (SiO2)n]. El Sílice comprende una parte sustancial de la corteza de la Tierra, es uno de los minerales más comunes de la Tierra, que existe en forma de cristalino (o «sílice libre») y formas amorfas. Es la forma cristalina el motivo de preocupación ${ }^{6}$. Altas exposiciones son frecuentes para los trabajadores de la fundición, mineros (pero muy variable dependiendo del contenido de sílice del mineral), canteros y arenadores. Bajas exposiciones son posibles cuando los polvos mezclados se inhalan. La población general no está expuesta a niveles suficientes para causar la enfermedad.

Las complicaciones de la silicosis incluyen la EPOC; infección por mycobacterias tuberculosis (Silicotuberculosis); infección por hongos oportunistas; artritis reumatoide y esclerodermia y riesgo aumentado de cáncer de pulmón ( 2 a 6 veces mayor), independiente de la asociación al tabaquismo ${ }^{7}$.

La Neumoconiosis por metales es el depósito de mineral en el parénquima pulmonar, en particular los minerales con elevado número atómico. pesados:

En la siguiente tabla (Tabla 2) mostramos las enfermedades por exposición a metales

Tabla 2. Enfermedades profesionales por exposición a metales pesados

\begin{tabular}{ll}
\hline ESTANNOSIS & Estaño $(\mathrm{Sn})$ (aleación $\mathrm{Sn}+\mathrm{Cu}$ forman el Bronce) \\
\hline SIDEROSIS & Hierro $(\mathrm{Fe})$ Diferente a la Hemosiderosis donde el hierro es de origen endógeno. \\
\hline BERILIOSIS & $\begin{array}{l}\text { Berilio }(\mathrm{Be}) \text {. Exposición aguda: Edema Agudo de Pulmón. Exposición crónica: } \\
\text { Sensibilización al Be que produce enfermedad símil a Sarcoidosis }\end{array}$ \\
\hline BAUXITOSIS & Aluminio $(\mathrm{Al})$ \\
\hline BARITOSIS & Bario $(\mathrm{Ba})$ \\
\hline COBALTO $(\mathrm{Co})$ & La exposición crónica produce Enfermedad Intersticial Pulmonar \\
\hline
\end{tabular}

Dentro de este grupo es importante mencionar la Enfermedad Crónica por Berilio ya que existe fuerte relación con la exposición profesional de los trabajadores de la industria de cobre y su aleación con berilio.

Enfermedad Crónica por Berilio (ECB) es una enfermedad profesional granulomatosa pulmonar y sistémica causada por la inhalación de berilio. La latencia de la enfermedad puede oscilar entre 1 y 30 años, pero generalmente se produce de 10 a 15 años después de la primera exposición. Presenta un curso variable, con agudizaciones y remisiones de sus manifestaciones clínicas. Sin embargo, la enfermedad suele ser progresiva.

El principal uso del berilio metálico se encuentra en la manufactura de aleaciones berilio-cobre y en el desarrollo de reactores nucleares. La adición de un $2 \%$ de berilio al cobre forma una aleación no magnética seis veces más fuerte que el cobre. Estas aleaciones berilio-cobre tienen numerosas aplicaciones en la industria de herramientas ya que no producen chispas, en las partes móviles críticas de aviones, así como en componentes clave de instrumentos de precisión, ordenadores, mecánicas, martillos, llaves y otras herramientas de berilio-cobre se emplean en refinerías petroleras y otras plantas en las cuales una chispa producida por piezas de acero puede ocasionar una explosión o un incendio. El berilio tiene muchos usos en la energía nuclear porque es uno de los materiales más eficientes para disminuir la velocidad de los neutrones, así como para reflejarlos.

Alergias de contacto: Se han evidenciado algunas alergias y dermatitis de contacto en trabajadores en contacto con el cuproníquel (aleación de $\mathrm{Cu}+\mathrm{Ni}$ ) y otros elementos tales como hierro y manganeso. Este metal no se corroe en agua de mar. Es comúnmente 
usada en muchas monedas modernas de color plateado como la moneda de un euro y la parte exterior de la moneda de dos euros.

Intoxicación aguda por sales de cobre o Fiebre por Metales: Una exposición aguda a las sales de cobre puede causar una intoxicación aguda que se presenta con síntomas similares a la gripe y se caracteriza por fiebre, escalofríos, mialgias, vómitos y leucocitosis ${ }^{8}$. Los síntomas iniciales pueden manifestarse después de un período de hasta 24 horas. La recuperación no se acompaña con efectos residuales para la salud.

Actualmente la importancia del cobre se debe a sus múltiples usos en la industria en general; su capacidad de reciclarse entre otras de sus características, ha permitido que aumente la explotación de forma considerable, sin tomar en cuenta todo lo esto ha traído consigo y como ha influido en la salud de los trabajadores de la industria del cobre, es por este motivo que nos hemos planteado los siguientes objetivos:

\section{OBJETIVOS}

La presente revisión sistemática tiene como objetivo principal:

Realizar una revisión bibliográfica que permita identificar las principales enfermedades profesionales que desarrollan los trabajadores en la industria de cobre.

Formulándose los siguientes objetivos secundarios:

Identificar las enfermedades profesionales más frecuentes que se producen en los trabajadores de diferentes sectores de la Industria del Cobre: Extracción, Manufactura y Reciclaje.

Comprobar si las principales enfermedades profesionales que desarrollan los trabajadores de los diversos sectores de la industria del cobre están directamente relacionadas con los niveles de exposición a cobre o con la exposición a otros elementos que se utilizan en la industria.

\section{METODOLOGÍA}

Se realizó una búsqueda en las bases de datos bibliográficas (BDB) MEDLINE (Pubmed), LILACS, Scielo, Cochrane Library y el Índice Bibliográfico Español de Ciencias de la Salud (IBECS), utilizando descriptores MesH-DeCS para establecer la estrategias de búsquedas («Copper»[Mesh]) AND «Occupational Diseases»[Mesh] y ((«Mining»[Mesh]) AND «Copper»[Mesh]) AND «Occupational Diseases»[Mesh], ((«Recycling»[Mesh]) AND «Copper»[Mesh]) AND «Occupational Diseases»[Mesh], ((«Manufacturing»[Mesh]) AND «Copper»[Mesh]) AND «Occupational Diseases»[Mesh], «Copper»[Mesh]) AND «Work»[Mesh], ("Copper»[Mesh]) AND «Toxicity» «[Mesh]

Adicionalmente se realizó una búsqueda manual a través portales como Google, páginas web institucionales como la de la OIT e INSHT. Asimismo, a partir de bibliografía referida en los artículos encontrados a través de la estrategia de búsqueda anterior.

Se utilizaron como criterios de inclusión:

- Estudios en humanos.

- Publicados en los últimos 20 años (1993-2013).

- Estudios que relacionan la exposición al cobre con minería, manufactura y reciclado.

- Tipo de estudios: ensayos clínicos, meta análisis, estudios de cohorte, estudios de casos y controles, revisiones sistemáticas y casos clínicos.

- Escritos en español, inglés, francés, portugués y alemán. 
Criterios de exclusión:

- Artículos que estudian el cobre como factor de riesgo fuera del ámbito laboral

- Estudios metabólicos del cobre como oligoelemento

- Estudios ambientales relacionados con la exposición al cobre

- Estudios en trabajadores de minería no relacionada con el cobre

A partir de la estrategia de búsqueda realizada en las distintas bases de datos descritas anteriormente se obtuvo una colección de 278 artículos. Una vez eliminados los artículos duplicados, redundantes, no pertinentes y aplicados los criterios de inclusión y exclusión preestablecidos, se obtuvo total de 14 artículos en esta primera búsqueda. Se completó la colección a través de una búsqueda manual obteniendo 6 artículos más para un total de 20 artículos. De los 20 artículos incluidos en nuestra revisión sistemática 2 correspondían a artículos de revisión que dada su importancia y pesar de que uno de ellos no cumplía estrictamente con el criterio de inclusión (año de publicación) formaban parte de las primeras investigaciones sobre este tema, por lo que hemos decidido incluir a la hora de elaborar los apartados de introducción, discusión y conclusiones. Del resto de artículos 9 eran estudios de cohorte, 2 artículos correspondían a estudios de casos y controles, 3 artículos a estudios descriptivos y 2 artículo era estudio transversal. Finalmente quedaron 16 artículos seleccionados para el análisis de resultados.

\section{RESULTADOS}

De los 16 artículos 6 se relacionaban con la aparición de enfermedades profesionales en trabajadores del sector de extracción de cobre, 10 en trabajadores de manufactura de cobre (de estos 10 artículos, 1 artículo se repite en ambas categorías: extracción y manufactura) y 2 artículos se referían a los trabajadores de la fundición y el reciclaje de cobre. (Tabla 3). 


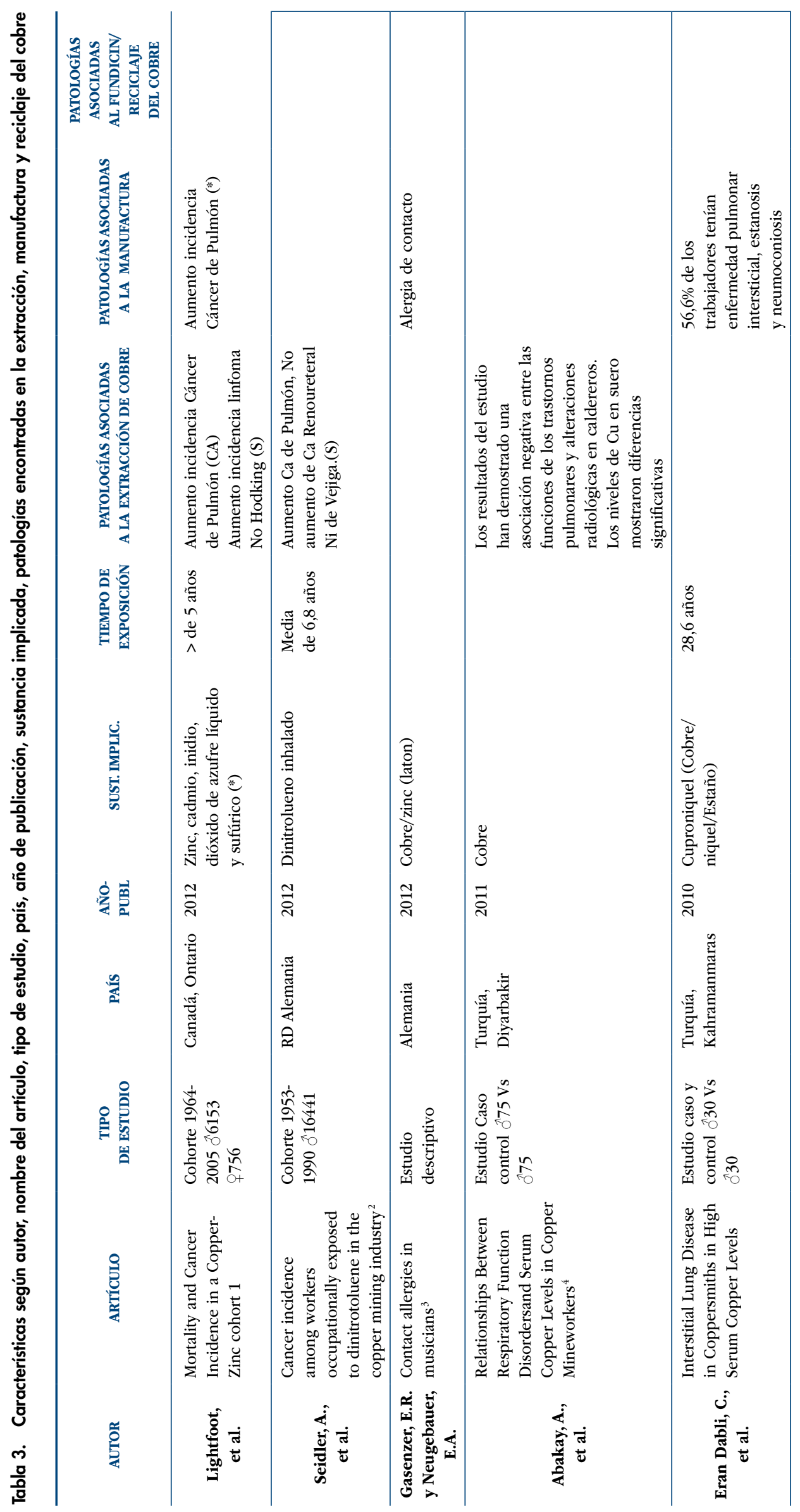




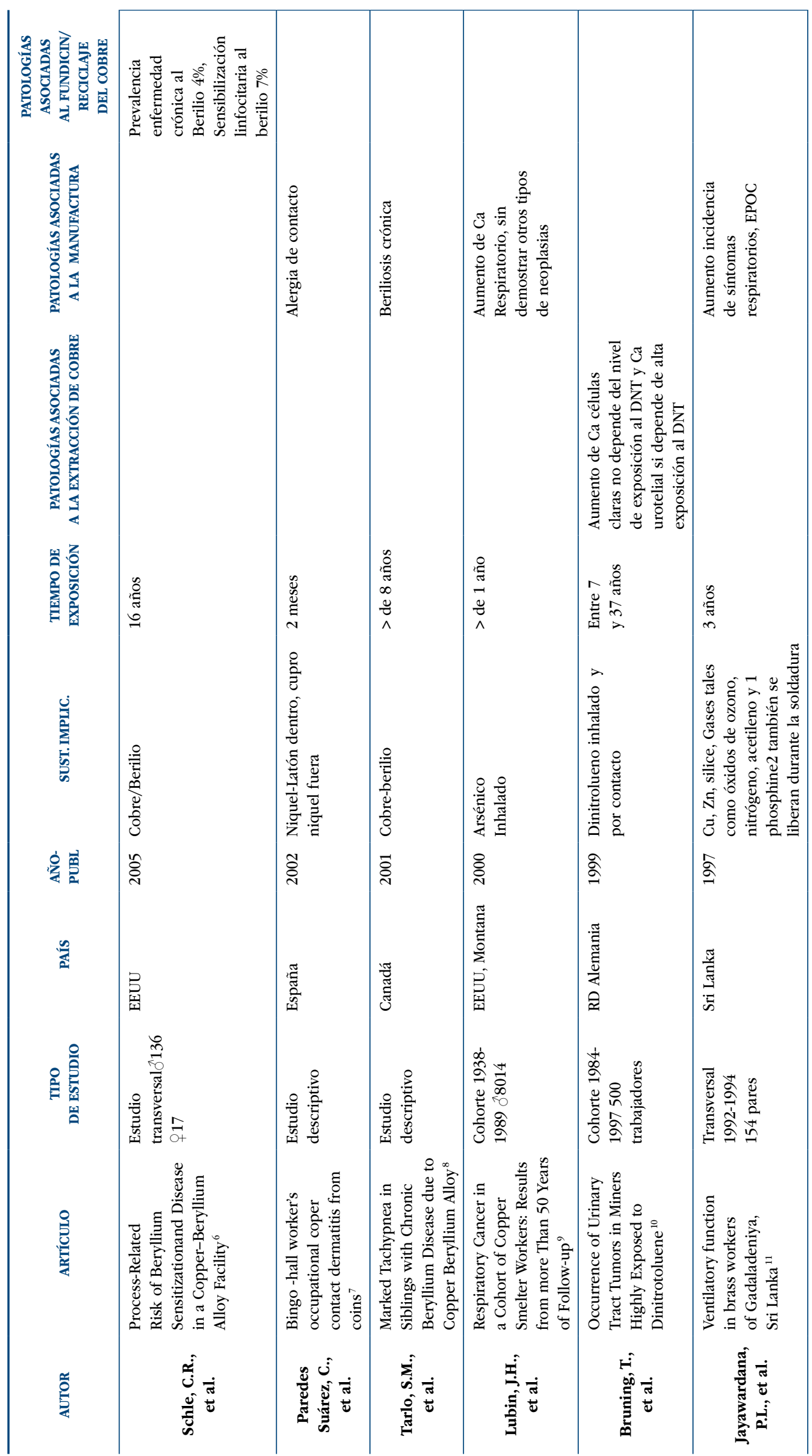




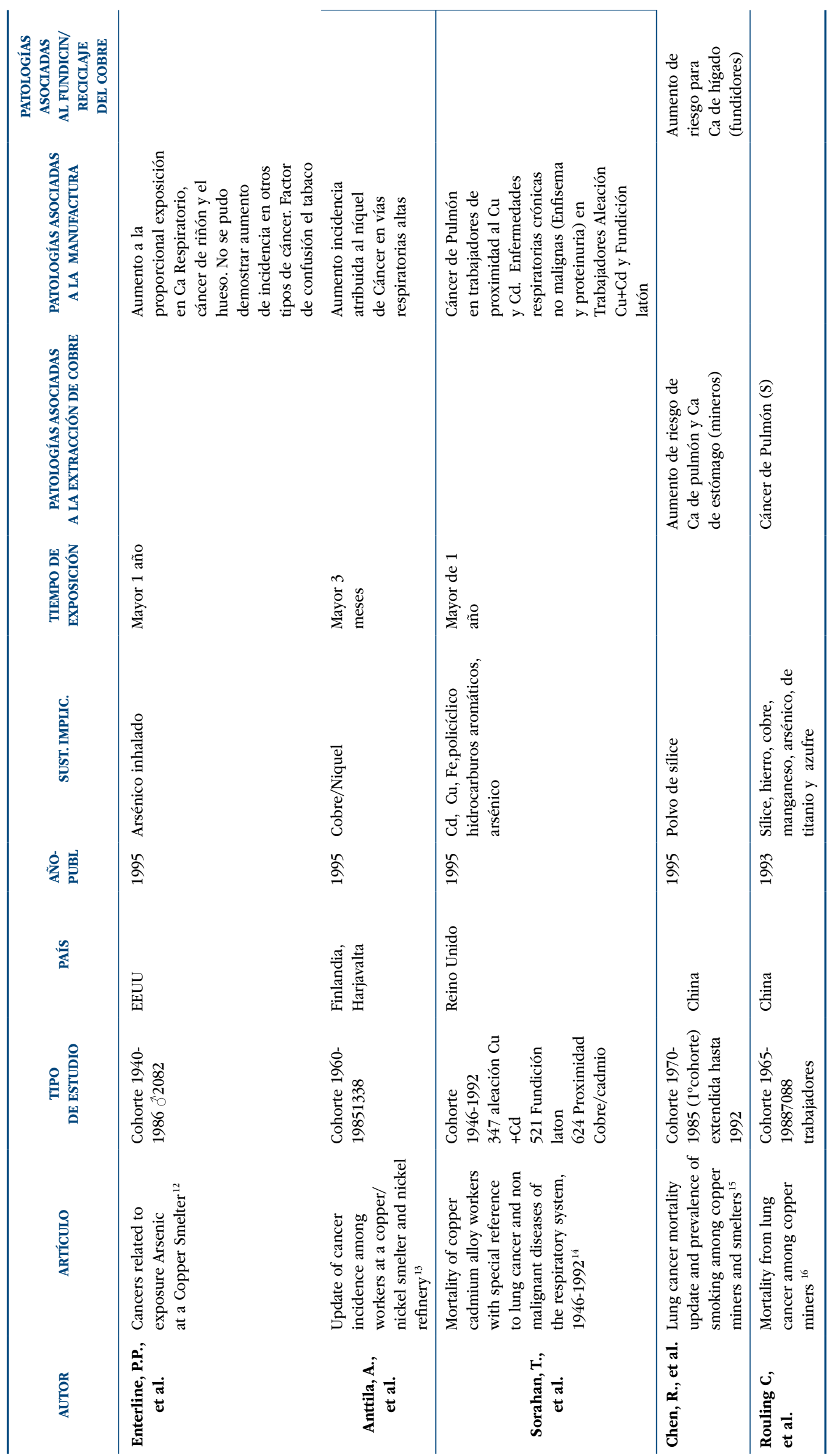


En nuestra revisión encontramos la aparición de varias patologías dentro del mismo artículo. Para facilitar el análisis de los resultados los hemos agrupado en 4 categorías: cáncer de pulmón y vías respiratorias, otros tipos de cánceres, enfermedades respiratorias crónicas y alergias.

10 artículos se referían al aumento de la incidencia de cáncer de pulmón y vías respiratorias, 5 se referían a otros tipos de cánceres (urotelial, Linfoma No Hodking, de estómago, de vejiga, de colon, de hueso, de hígado), 6 describían enfermedades respiratorias crónicas (neumoconiosis, EPOC), 2 reportaron alergias de contacto.

Gráfico 1. Enfermedades Profesionales en la Industria del Cobre

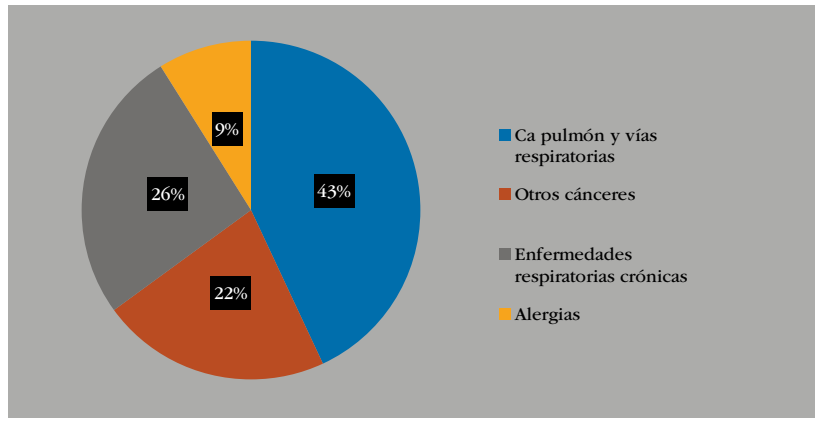

Las enfermedades identificadas en los trabajadores de la extracción del cobre fueron principalmente cáncer de pulmón y vías respiratorias ( 5 artículos) y otros cánceres (3 artículos), enfermedades respiratorias crónicas (1 artículo).

Gráfico 2. Enfermedades Profesionales en la extracción de Cobre

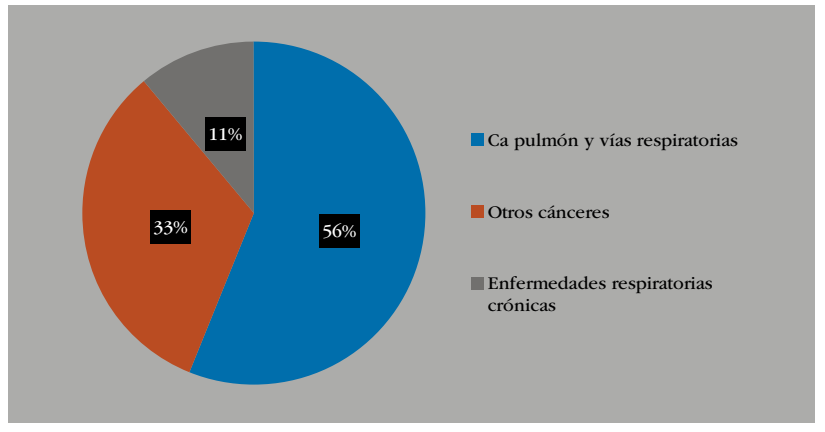

Las enfermedades profesionales identificadas en la industria de manufactura del cobre son cáncer de pulmón y vías respiratorias ( 5 artículos), otros cánceres (1 artículos), enfermedades respiratorias crónicas ( 4 artículos), alergia de contacto ( 2 artículos).

\section{Gráfico 3. Enfermedades Profesionales en la manufactura del cobre}

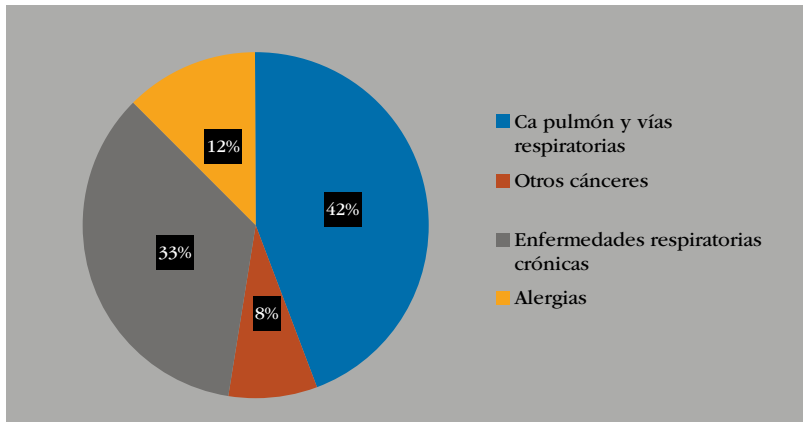

Las enfermedades profesionales identificadas en la fundición y reciclaje de cobre son otros cánceres (1 artículo) y enfermedades respiratorias crónicas ( 2 artículos). 
Gráfico 4. Enfermedades Profesionales en el reciclaje

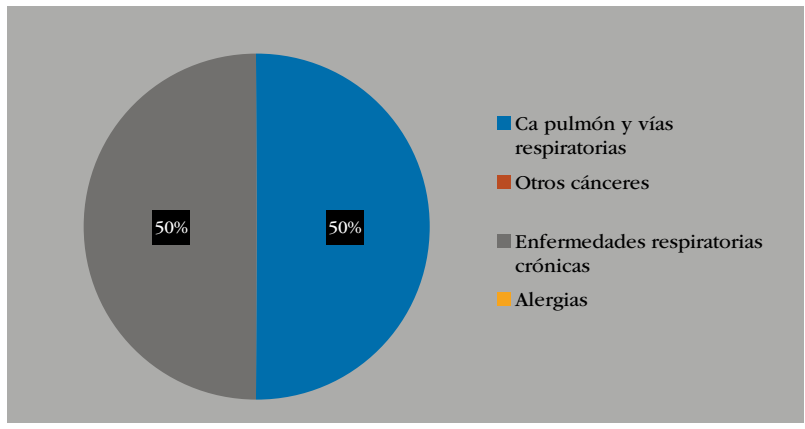

Los países con más estudios realizados con respecto al tema de nuestra revisión son: Estados Unidos, Alemania seguido de China, Turquía, Canadá, España, Finlandia, UK y Sri Lanka. En la Tabla 4 se muestra el número de artículos revisados por países.

Tabla 4. Número de artículos revisados por países

\begin{tabular}{|c|c|}
\hline Países & N. ${ }^{o}$ de artículos \\
\hline Alemania & 3 \\
\hline Estados Unidos & 3 \\
\hline Turquía & 2 \\
\hline Canadá & 2 \\
\hline China & 2 \\
\hline España & 1 \\
\hline Finlandia & 1 \\
\hline Reino Unido & 1 \\
\hline Sri Lanka & 1 \\
\hline
\end{tabular}

\section{RESUMEN DE LAS PRINCIPALES CARACTERÍSTICAS DE LOS ARTÍCULOS ESTUDIADOS}

\section{CÁNCER DE PULMÓN Y OTROS TIPOS DE CÁNCERES}

\section{Rouling C et al. ${ }^{24}$ (1993)}

Estos autores evaluaron a través de una cohorte histórica de trabajadores de la mina de cobre de Tongling en Anhui provincia de China, desde 1969 a 1988. Se evidenció que estaban expuestos a polvo y posible radiactividad (Radón) por los malos sistemas de ventilación. Se observó mayor mortalidad por Cáncer de Pulmón en los mineros subterráneos. En 1950 el sistema de ventilación fue por perforación seca y a partir de 1963 húmeda. Se encontraron componentes como sílice, hierro, cobre, manganeso, arsénico, titanio, y azufre. En este estudio la concentración de arsénico fue muy baja y más alta de sílice y del hierro. En este trabajo el tabaquismo podría haber sido un sesgo de confusión.

\section{Enterline PP et al. ${ }^{20}$ (1995)}

Estos autores realizaron un estudio de cohorte con 2802 hombres que trabajaban en una fundición de cobre expuestos a arsénico inhalado, durante uno o más años entre el período 1940-1964. Y se estudió la mortalidad durante el período 1941-1986. Hubo una relación positiva entre la exposición al arsénico en el aire y el cáncer pulmonar, cáncer de riñón y hueso, aunque no se ha relacionado de forma significativa ningún otro tipo de neoplasia. También se observó mayor incidencia de enfermedad pulmonar: bronquitis 
crónica, enfisema y asma. El hábito tabáquico pudo haber sido un factor de confusión en este estudio.

\section{Anttila A et al. ${ }^{21}$ (1995)}

En este estudio se evaluó la incidencia de cáncer en 1.388 trabajadores empleados durante al menos 3 meses en la fundición de aleación cobre / níquel en la refinería de níquel en Harjavalta Finlandia. Había 1.155 trabajadores expuestos al níquel durante el período 1960-1985. En la fundición (566 trabajadores), taller de reparación (239 trabajadores), o refinería (418 trabajadores). La incidencia de cáncer fue seguida a través de los archivos del Registro Finlandés del Cáncer hasta el 31 de diciembre de 1995. Para el cáncer en general y para, a priori, seleccionar los tipos de cáncer específicos se calculó el número de casos esperados con una tasa de incidencia estandarizada (SIR), controlado por edad, sexo, y el período de tiempo y utilizando las estadísticas de la región como referencia. Se observó un pequeño aumento en la incidencia de cáncer de pulmón, que alcanzó significación estadística entre los trabajadores con una latencia superior a 20 años en los trabajadores de fundición expuestos a compuestos de níquel insoluble. Entre los trabajadores de la refinería, que estuvieron expuestos principalmente al sulfato de níquel en niveles inferiores a $0,5 \mathrm{mg} / \mathrm{m} 3$, así como a las bajas concentraciones de otros compuestos de níquel, se produjo un aumento del riesgo de cáncer nasal (SIR 41,1, IC del 95\%: 4,97 a 148).

\section{Sorahan T et al. 22 (1995)}

En este estudio realizado en Inglaterra y Gales se evalúa la mortalidad por cáncer de pulmón y enfermedades del sistema respiratorio no malignas. Se comparó un grupo de 347 trabajadores de la aleación cadmio-cobre, 624 trabajadores empleados en el almacén de cobre-cadmio, 524 trabajadores de la fundición de hierro y latón, todos hombres. Se investigó durante el período 1946-1992. Todos los sujetos fueron empleados en este tipo de trabajo en el período 1922-1978. Este estudio mostró un aumento significativo de cáncer de pulmón entre los trabajadores del almacenamiento pero no en los trabajadores del hierro y la fundición de latón (trabajadores del almacén cobrecadmio: 55 observados, esperado 34.3, SMR (tasa de mortalidad estandarizada) 160, IC del 95\% 121 a 209, P <0-01; trabajadores de la fundición del hierro y latón: observados 19, esperados 17-8, SMR 107, IC del 95\%: 64 a 167). Por otro lado, se observó un aumento de las enfermedades respiratorias no malignas en los tres grupos (trabajadores de la aleación: observado 54, esperado 23 5, SMR 230, IC del $95 \% 172$ a 300, P <0*001; trabajadores del almacén: observado 71, espera 43 0, SMR 165, IC del 95\%: 129 a 208, P <0 * 001;trabajadores de la fundición del hierro y el latón: 34 observados, esperados $17 * 1$, SMR 199, IC del 95\%: 137 a 278, P <0,01).

Estos autores concluyeron que la exposición a humo de óxido de cadmio aumenta el riesgo de mortalidad por enfermedades crónicas del sistema respiratorio no malignas. Los resultados no apoyaron la hipótesis de que la exposición al humo de óxido de cadmio aumenta el riesgo de mortalidad por cáncer de pulmón. Se atribuye el aumento de la incidencia de cáncer de pulmón a la manipulación del arsénico en los trabajadores del almacenamiento del cobre-cadmio.

\section{Chen $\mathrm{R}$ et al. ${ }^{23}$ (1995)}

El propósito de éste estudio fue analizar la mortalidad de mineros y fundidores en una mina de China con especial referencia a carcinoma de pulmón y también determinar la prevalencia de tabaquismo. Se realizaron dos estudios de cohorte. Primer estudio se realizó desde 1970-1985 y se informó que en comparación con la población general existía mayor riesgo de cáncer de pulmón para los mineros de cobre RSM (Tasa de mortalidad estandarizada) $185, \mathrm{P}<0.05$ ) pero no en los fundidores de cobre (RSM 90, P $>0.05$ ), aunque en el último grupo había un incremento de mortalidad total por cáncer (RSM 148, P-0.05). El segundo estudio se realizó desde el 1985 hasta 1992 junto con el 
estudio de prevalencia de tabaquismo de la cohorte y de la población general. Se aplicó un cuestionario sobre hábito tabáquico en tres muestras, elegidas al azar de los mineros del cobre $(\mathrm{N}=1.125)$, fundidores $(\mathrm{N}=603)$ y población general $(\mathrm{N}=1517)$ de la ciudad de Tongling. Las diferencias en las tasas de tabaquismo entre los grupos se calcularon a través de Chi Cuadrado. Se evidenció que la prevalencia de tabaquismo era más alta entre los mineros de cobre que en la población general $(71.7$ vs $64.3 \%, \mathrm{P}<0.001)$ pero la prevalencia de tabaquismo entre los fundidores de cobre era significantemente menor ( 57.4 vs $64.3 \%, \mathrm{P}<0.005)$. Estos datos se deben a que estaba prohibido fumar en el área de fundición. Los mineros de cobre tenían tendencia a fumar más durante los periodos de inactividad dentro de la mina y los efectos perjudiciales podrían haber sido incrementados por mala ventilación.

Este estudio concluyó que hubo aumento en la mortalidad por cáncer de pulmón esófago, estómago e hígado entre los mineros y fundidores. El riesgo del cáncer de pulmón entre los fundidores de cobre no era significativo (SMR 102, 95 CI 53-178) mientras el riesgo para el cáncer de hígado sí era significativo (SMR 178, 95\% CI 105-281), en los mineros de cobre el riesgo para cáncer de pulmón era significativamente alto (SMR 152) así como el aumento de riesgo de cáncer de estómago (SMR141, 95\% CI 116169). Estos mineros estaban expuestos mayormente al polvo de sílice, para el ese momento se sospechaba que podría ser un carcinógeno. También en este estudio se llegó a la conclusión de que el tabaquismo de manera sinérgica puede aumentar el riesgo de cáncer de pulmón ocupacional.

\section{Bruning T et al. ${ }^{18}$ (1999)}

Realizaron un estudio de cohorte con 500 trabajadores de la minería subterránea de cobre de la República Democrática Alemana, entre 1984 y 1997 en el cual observaron 6 casos de cáncer urotelial y 14 casos de cáncer de células renales, debidas presuntamente a las altas exposiciones a explosivos que contienen dinitrotolueno (DNT). La duración de la exposición de los trabajadores osciló entre 7 a 37 años, y el período de latencia varió desde 21 hasta 46 años. Las incidencias de los tumores tanto de células uroteliales como renales en este grupo fueron muy superiores a lo esperado, sobre la base de los registros de cáncer de la República Democrática Alemana. Un grupo representativo de 183 mineros expuestos al DNT fueron entrevistados sobre historia laboral y agrupados en cuatro categorías de exposición. De los14 casos de tumores de células renales no reveló ninguna dependencia en relación a la dosis de explosivos, en cualquiera de las cuatro categorías de exposición, considerando el grado de exposición y vía (respiratoria/contacto); mientras que los casos de tumores uroteliales se limitaron principalmente a la alta exposición.

El 90\% de los mineros declararon no haber inhalado el humo de las explosiones, y el 60\% afirmó inhalación del humo del tabaco diariamente. No se realizaron sub-cohortes para determinar si el tabaquismo fue un factor de confusión.

\section{Lubin JH et al. ${ }^{17}(2000)$}

Los autores siguieron a 8014 trabajadores varones que fueron empleados durante 12 meses o más antes de 1957 en una fundición de cobre de Montana, USA durante el período 1938 hasta 1989.

En este artículo analizamos los resultados de un nuevo seguimiento de un gran estudio de cohortes de Lee-Fraumenide en trabajadores de la fundición de cobre expuestos al arsénico inhalado. Se realizó un análisis detallado de la relación entre la exposición al arsénico inhalado y la mortalidad por cáncer respiratorio y otras causas de muerte. Un total de 4.930 (62\%) habían fallecido, de los cuales 446 trabajadores fallecieron por cáncer respiratorio. Este estudio demostró un aumento de la incidencia de cáncer respiratorio, sin demostrar otros tipos de neoplasias.

Los investigadores realizaron mediciones de arsénico en el aire en 11 de los 33 departamentos de la fundición y la medición de arsénico urinario en casi todos los 
trabajadores. El arsénico inhalado se ha correlacionado positivamente con arsénico urinario. Entre todos los trabajadores se observó de manera significativa SMRs (SMR $=1,14$ ) aumento de la incidencia de algunos tipos de cánceres (SMR $=1,13)$ principalmente cáncer de las vías respiratorias (SMR = 1,55), y el cáncer de pulmón ( $\mathrm{SMR}=1,58$ ); asimismo, evidenciaron significativamente elevadas las SMRs por otras enfermedades como algunas relacionadas con el sistema nervioso y órganos de los sentidos (SMR = 1.31), enfermedades respiratorias no malignas $(\mathrm{SMR}=1.56)$, enfisema $(\mathrm{SMR}=1,73)$, estados morbosos mal definidos $(\mathrm{SMR}=2,26)$ y causas externas $(\mathrm{SMR}=1,35)$. Estos autores observaron disminución de mortalidad por todas las causas para todos los cánceres del sistema hematopoyético y linfático $(S M R=0.66)$, particularmente el linfoma $(\mathrm{SMR}=0,50)$ y mieloma múltiple $(\mathrm{SMR}=0,36)$.

El análisis de este estudio reveló un aumento significativo y una la relación lineal entre la alta exposición al arsénico inhalado y el riesgo de desarrollar cáncer de las vías respiratorias. Ninguna otra causa de la muerte estaba relacionada con la exposición al arsénico inhalado. Había un aumento del riesgo de cáncer de las vías respiratorias entre los trabajadores que pasaron más tiempo en las áreas de trabajo con mayores niveles de arsénico.

\section{Lightfoot NE et al. ${ }^{9}$ (2012)}

En un estudio de cohorte en trabajadores de la minería de cobre y zinc en Ontario, Canadá se incluyeron a 6.153 varones y 756 mujeres trabajadores, recogiendo la información de una base de datos del Registro de Cáncer de Ontario: Ontario Cancer Registry (OCR). En los trabajadores varones de toda la cohorte se observó un aumento significativo de la incidencia para el cáncer de pulmón SIR (SIR = 124, IC $95 \%=102-15$ ). Para los mineros subterráneos se ha encontrado un aumento estadísticamente significativo en la incidencia de Linfoma no Hodgkin (SIR = 232, IC $95 \%=111-426$ ). En este mismo estudio se ha detectado un aumento significativo de la incidencia de cáncer de pulmón en los trabajadores de minas a cielo abierto ( $S I R=272,95 \%$ IC $=124-517$ ) y aumento de la mortalidad por cáncer de pulmón (SIR = 383, IC $95 \%=153-789$ ) en trabajadores con más de 5 años de trabajo; también se ha asociado un aumento significativo en la mortalidad por enfermedad cardiovascular (SMR $=204$, IC $95 \%=114-336)$. En los trabajadores de concentración y mantenimiento se ha observado aumento significativo de la incidencia de cáncer de pulmón y vías respiratorias (SIR = 191, 95 \% CI = 102 a 327).

\section{Seidler A et al. ${ }^{10}$ (2012)}

Este trabajo analiza una cohorte compuesta por 16.441 trabajadores nacidos entre 1920 y 1974 que fueron empleados entre 1953 y 1990 en una de las dos minas de cobre subterráneas en la antigua República Democrática Alemana, que fueron seguidos analizando la incidencia de distintos tipos de cáncer, desde el 1961 hasta el 2005. Las SIR para todos los tipos de cáncer no fueron significativamente elevados en la cohorte (SIR = 1,04; intervalos de confianza del 95\% (IC 0,96 a 1,14). Se encontró un aumento de incidencia del cáncer de pulmón ( $\mathrm{SIR}=1,29 ; 1,13$ a 1,46), pero no en el cáncer de riñón (SIR = 1,01, IC del 95\%: 0,79 a 1,27) o del cáncer de vejiga (SIR = 1,04, IC del 95\%: 0,82 a 1,30). La incidencia de cáncer de riñón y vejiga están relacionados al tiempo de exposición. Se hicieron dos cohortes de fumadores más de 20 años y menos de 20 años de exposición al DNT para evitar el sesgo de confusión. De un total de 401 miembros fumadores de la sub-cohorte se observó un 76\% de mortalidad por cáncer de pulmón en trabajadores con $\leq 20$ años de exposición al DNT y un $75 \%$ en los trabajadores con >20 años de exposición. Demostraron así que la mortalidad por cáncer de pulmón no se asoció de manera significativa con el tabaquismo y si con la exposición al DNT. 


\section{ALERGIAS}

\section{Paredes Suárez, C et al. ${ }^{15}$ (2002)}

Este estudio de Santiago de Compostela describe el caso de un trabajador del Bingo que había estado continuamente en contacto con monedas de 2 euros que contienen níquel y cobre durante 2 meses y había desarrollado dermatitis en las puntas de los dedos, párpados superiores y cantos externos lo cual fue atribuido a la exposición a níquel.

\section{Gasenzer ER et al. " (2012)}

En este estudio realizado en Alemania se describen reacciones alérgicas a distintos materiales en músicos que utilizaban instrumentos de viento. En los que nos interesa en relación al cobre, describe la alergia de contacto por materiales con latón (aleación de zinc y cobre) y se realizan recomendaciones sobre la elección de instrumentos musicales y la calidad de materiales.

\section{ENFERMEDADES RESPIRATORIAS NO MALIGNAS}

\section{Jayawardana PL et al. ${ }^{19}$ (1997)}

Se trata de un estudio de 2 cohortes que se llevó a cabo en una fábrica de productos de bronce en Gadaladeniya, en el distrito de Kandy, Sri Lanka. Este estudio se centró en trabajadores de latón. El grupo de estudio fue seleccionado al azar. El grupo control fue seleccionado de la población general emparejados por edad y por muestreo por conglomerados. Había un total de 154 pares para el análisis final. Se aplicó un cuestionario para determinar la prevalencia de síntomas respiratorios. La capacidad vital forzada (FVC), volumen espiratorio forzado en el primer segundo (FEV1), tasa de flujo espiratorio forzado el $50 \%$ de la FVC (FEF25 \% - $75 \%$ ) y la tasa de flujo espiratorio máximo (FEM) fueron medidos a través de la espirometría. La radiografía de tórax se realizó en aquellos con 5 o más años de servicio. Síntomas como tos, flemas, disnea fueron significativamente mayores en los trabajadores del latón en comparación con el grupo control. La capacidad ventilatoria fue significativamente menor en todos los indicadores excepto FVC. Fumar no tuvo efecto significativo.

Se observó a los trabajadores de latón para estar en una forma significativa mayor riesgo de desarrollar síntomas respiratorios. Además de una disminución de la capacidad ventilatoria. Puede ser el resultado de una combinación de exposiciones atribuible al ambiente de trabajo.

\section{Tarlo SM et al. ${ }^{16}$ (2001)}

Se trata de un estudio que describe dos casos únicos en una fábrica de 120 trabajadores de Canadá. Estas empleadas eran dos hermanas biológicas que trabajaron más de ocho años en la misma fábrica de fundición de metales sobre todo con aleaciones de cobre/berilio, quienes desarrollaron Enfermedad Crónica por Berilio. Las dos trabajaron en un ambiente lleno de polvo y con mala ventilación y solo una de ellas utilizaba la mascarilla de papel en los últimos dos años. El trabajo de las dos consistía en cepillado y limpieza de moldes que contenían polvo de metales. Aproximadamente el 5-10\% de las veces la pieza de fundición era aleación de cobre (98\%) y berilio (2\%). El diagnostico se confirmó por biopsia pulmonar y transformación linfocítica por berilio, esto apoya la base genética de beriliosis y marcada taquipnea que acompaña a esta enfermedad. La exposición a este metal produce diferentes enfermedades desde granulomas cutáneos hasta cáncer de pulmón. La ECB continúa ocurriendo en individuos expuestos en industrias donde se utiliza berilio con una prevalencia entre 2-6\%. 


\section{Schuler CR et al. ${ }^{14}$ (2005)}

Este estudio presenta el primer estudio médico de una fundición que se encarga principalmente de aleaciones de cobre-berilio. De los 185 empleados invitados a participar, 153 (83\%) completaron las entrevistas y 152 se les extrajo muestras de sangre para detectar la proliferación de linfocitos sensibilizados al berilio (BeLPT). La mayoría de los participantes eran hombres $(89 \%, 136 / 153)$ y de color blanco o blanco hispana (95\%, 146/153), su edad media fue de 44 años (rango 22-68). La mediana de tiempo de exposición fue de 16 años (rango <1-45) para los participantes en el estudio, 11 participantes también estuvieron expuestos al berilio antes de la contratación (rango 1-16 años de tiempo adicional desde la primera exposición). En las personas diagnosticadas con el ECB, todos tenían un BeLPT positivo y 3 tuvieron un aumento del porcentaje de linfocitos en el LBA. Los individuos diagnosticados con el ECB (granulomas en biopsias) no presentaban alteraciones significativas de la función pulmonar y la fibrosis no aparentes en biopsias o en las radiografías de tórax. La prevalencia de sensibilización también era más alta en los trabajadores de la varilla y producción de alambre (recocido y decapado). También la prevalencia de sensibilización fue más alta en los trabajadores que reportaron incidentes de exposición sin utilizar mascarilla.

\section{Abakay A et al. ${ }^{12}$ (2012)}

Este estudio de casos y controles realizado en un grupo de trabajadores de la minería en Turquía a través de las mediciones de polvo en las minas de cobre mostró que la concentración media de $\mathrm{Cu}$ fue de $2.182 \mu \mathrm{g} / \mathrm{m}^{3} / 24 \mathrm{~h}$. Todos los trabajadores de minas

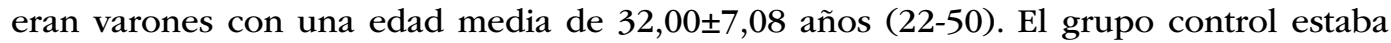
formado por 75 hombres que no tenían síntomas, con una edad media de 32,46 $\pm 6,86$ años (23-49). Un total de 44 mineros (58,6\%) eran fumadores y 37 casos de control (48,3\%) eran fumadores. No se encontraron diferencias significativas entre los dos grupos de edad y tabaquismo ( $p>0,05)$. Se encontraron valores espirométricos de los mineros más bajos que los del grupo de control $(\mathrm{p}<0,05)$. El análisis de laboratorio de las muestras de suero mostró que los niveles de $\mathrm{Cu}$ en suero de los mineros fueron $0,80 \pm 0,62 \mu \mathrm{g} / \mathrm{ml}$ y los niveles de $\mathrm{Cu}$ en el suero en el grupo de control eran $0,60 \pm 0,39 \mu \mathrm{g} / \mathrm{ml}$. Nivel de $\mathrm{Cu}$ en el suero fue significativamente mayor en el grupo de trabajadores de minas en comparación con el grupo control $(\mathrm{p}=0,017)$. El cuestionario reveló que $38(50,7 \%)$ de mineros tenía historia crónica de esputo, 26 (34,7\%) tenían tos crónica, 25 (33,3\%) tenían disnea, y 11 $(14,7 \%)$ de los trabajadores habían tenido dolor en el pecho. El examen físico reveló que 8 mineros habían tenido crepitantes finos bilaterales en las bases pulmonares y cinco tenían roncus espiratorios. El plazo promedio de empleo para la minería era 3,97 $\pm 1,46$ años (0,5-6). El grupo de la minería se dividió en dos grupos por período de trabajo, los que trabajaron $\leq 3$ años, y los que han trabajado $>3$ años.

Se observó una correlación positiva significativa entre el nivel de $\mathrm{Cu}$ en suero y la duración de trabajo dentro de las minas $(r=0,295, p=0,013)$. Los resultados de las pruebas de función pulmonar revelaron un patrón normal en el 64\% de mineros, enfermedad respiratoria restrictiva en el $29,3 \%$, y la de tipo obstructivo se vio trastornos de la función pulmonar en el $6,7 \%$ de los trabajadores. Los niveles séricos de cobre fueron significativamente mayores en el grupo con trastornos de la función pulmonar tipo restrictivo $(1,36 \pm 0,62 \mu \mathrm{g} / \mathrm{ml})$, tipo obstructivo $(0,90 \pm 0,55 \mu \mathrm{g} / \mathrm{ml})$ y los grupos patrón de función respiratoria normal $(0,53 \pm 0,43 \mu \mathrm{g} / \mathrm{ml})(\mathrm{p}<0.001)$. Se evidenció una correlación negativa entre el nivel de $\mathrm{Cu}$ en suero y la FVC $(\mathrm{r}=-0,593, \mathrm{p}<0,001)$ y entre el nivel de $\mathrm{Cu}$ en suero y FEV1 en el grupo de la minería $(r=-0,600, p<0,001)$.

Entre los 75 trabajadores, 6 sujetos (8\%) tenían nódulos pulmonares, y 3 sujetos (4\%) tuvieron Fibrosis Intersticial. Se determinaron radiológicamente las anomalías del parénquima pulmonar. La frecuencia de los hallazgos radiológicos no fue estadísticamente significativamente entre el grupo de $\leq 3$ años de tiempo de trabajo y el grupo de $>3$ años de tiempo de trabajo $(\mathrm{p}>0,05)$. Los pacientes con anomalías radiológicas del parénquima 
tuvieron significativamente mayores niveles séricos de cobre que aquellos sin anomalías del parénquima $(1,53 \pm 0,52$ vs. $0,71 \pm 0,52 \mu \mathrm{g} / \mathrm{ml}$, respectivamente, $\mathrm{p}=0,002$.

\section{Eren Dabli C et al. ${ }^{13}$ (2012)}

Este estudio de casos y controles se realizó con 30 trabajadores caldereros en una fábrica en Turquía, todos varones con una edad media de 47,96 \pm 13,54 años (26-80). Tenía como grupo control 30 hombres asintomáticos con una edad media de 45,90 $\pm 11,69$ años (30-70). La duración media del período de trabajo fue 28,63 $\pm 14,33$ años (8-62); 12 de los trabajadores eran fumadores. No se detectó ninguna relación entre el período de trabajo y el nivel de cobre en suero ( $\mathrm{p}>0,05)$.

Ninguno de los sujetos tenía antecedentes de exposición a largo tiempo para el asbesto. Ninguno de los sujetos tenía comorbilidades tales como EPOC, otras enfermedades pulmonares, insuficiencia cardíaca congestiva, diabetes mellitus, o hipertensión. El cuestionario reveló que $8(26,7 \%)$ sujetos tenían tos crónica, 9 (30,0 \%) sujetos habían presentado disnea, 5 (16,7\%) sujetos tenían dolor en el pecho, y 11 (36,7 \%) sujetos tenían historia crónica de esputo. Las pruebas de función pulmonar mostraron que 6 sujetos tenían un patrón obstructivo, y 7 sujetos patrón mixto. Se encontraron valores espirométricos de los trabajadores menor que en el grupo control, pero la diferencia no fue significativa. Se detectó relación entre el nivel sérico de cobre y el valor del FEV1 disminuido en los trabajadores con respecto al grupo de control $(p<0,05)$. De 30 caldereros, en 17 de ellos la TACAR mostró un patrón anómalo con enfermedad pulmonar intersticial difusa, mientras que 13 tenían hallazgos en la TACAR normales. De los 17 hallazgos de la TACAR anormales $10(58,8 \%)$ son por enfermedad pulmonar intersticial tipo bronquiolitis respiratoria, 5 (29,4\%) neumonía intersticial no específica, y 2 (11,8 \%) neumonía intersticial.

El patrón de la TACAR más prevalente fue el patrón micronodular como se vio en 7 (23\%) trabajadores. Ninguno de los sujetos tenía calcificaciones pleurales en sus hallazgos radiológicos. El análisis de las muestras de suero mostró que los niveles de cobre en suero de los trabajadores fue $0,93 \pm 0,14 \mathrm{mg} / \mathrm{L}$ mientras que el nivel de cobre en suero en el grupo control fue $0,70 \pm 0,14 \mathrm{mg} / \mathrm{L}$, observándose una diferencia estadísticamente significativa entre los dos grupos $(\mathrm{p}<0,05)$.

\section{DISCUSIÓN}

Los hallazgos de nuestro estudio se han basado en los resultados obtenidos de estudios principalmente de cohorte y de casos y controles, en los cuales se demuestra la clara asociación entre la exposición laboral de trabajadores de la industria del cobre y una alta tasa de incidencia de distintos tipos de cánceres; principalmente el cáncer de pulmón y vías respiratorias, seguido de enfermedades respiratorias crónicas como las neumoconiosis y la EPOC. Las patologías menos frecuentes son cánceres de otras localizaciones diferentes al pulmón y a las vías respiratorias (riñón, urotelial, estómago, hígado, hueso, linfoma No Hodking) y en último lugar las alergias de contacto.

Es importante tener en cuenta que las enfermedades evidenciadas por los distintos investigadores, fueron definidas principalmente por los elementos, procedimientos y sustancias utilizadas en combinación con el cobre, así como el ambiente en que se desarrollaron las distintas actividades del sector como lo son: la extracción, manufactura, fundición y reciclaje. Estos diversos factores determinaron la aparición de las principales patologías mencionadas previamente sin evidenciar una correlación directa entre el cobre en su forma aislada "per se» y la aparición de patologías en los trabajadores de industria del cobre en general. Lo que si fue evidenciado hace mucho tiempo por Cohen SR et al. (1974) ${ }^{17}$ quienes en su revisión recopilaron diferentes aspectos de la toxicidad del cobre en sentido general y especialmente como potencial peligro ocupacional. Estos investigadores demostraron que las principales vías de exposición eran la vía tópica, 
inhalatoria y por ingesta afectando a diferentes órganos: piel (dermatitis de contacto por sales o polvo de cobre), anejos de piel (coloración verdoso negra del pelo en casos de exposición crónica), afectación ocular (conjuntivitis y edema de párpados), sistema respiratorio (congestión nasal y faríngea, ocasionalmente ulceración de septo nasal por exposición a polvo y humo), sistema gastrointestinal (sabor metálico, nauseas, ardor en epigastrio, vómitos de contenido verdoso, diarrea, sialorrea, melena, ictericia), renal (hemoglobinuria y hematuria), sistema cardiovascular (hipotensión), neurológicos (coma por uremia). También ha sido descrito malestar general similar al de la gripe, sensación de frio y calor, pesadez en la cabeza en pulidores de placas de cobre y fiebre de los metales. El diagnóstico rápido de la intoxicación se establece por medición de cobre en orina de 24 horas. Estos autores también señalan que aunque la toxicidad por cobre puede ocurrir con niveles de exposición elevados, el cobre es un oligoelemento esencial para la salud humana, ya que es un cofactor para varias enzimas oxidativas y que la intoxicación aguda por cobre es poco frecuente en los seres humanos y en gran parte el resultado se debe a la ingestión de sales de cobre. Los efectos de las sales de cobre en la carcinogénesis no se han demostrado. Señalan además, que la evidencia más clara de una asociación entre el cáncer y el trabajo en la minería y procesamiento de metales está en relación con el níquel. Mientras que otros autores Lubin JH et al. Enterline PP et al., Sorahan $\mathrm{T}$ et al. y Rouling $\mathrm{C}$ et al. asociaron la aparición del cáncer de pulmón a otros compuestos como el arsénico ${ }^{17,20,22,24}$.

Estudios llevados a cabo en diversos lugares han sugerido un mayor riesgo de cáncer de pulmón y vías respiratorias en trabajadores de la minería y en el procesamiento del cobre con sus aleaciones.

Otro hallazgo significativo en el cual fue difícil afirmar que el cobre tiene relación directa como causante de Fiebre de los Metales o Síndrome Similar a la Fiebre de los Metales fue el estudio de Borak J, et al. (2000) ${ }^{25}$ quienes realizaron una revisión sistemática de la literatura médica en el que se recogen siete informes sobre la relación causal entre el polvo y humo de cobre y Fiebre de los Metales, así como también un Síndrome semejante a la Fiebre por Metales. En sus informes se apreciaba la exposición de trabajadores (cortadores del latón) expuestos a mezcla de níquel, zinc y cobre, un trabajador de la fundición expuesto a mezcla de berilio, aluminio y cobre, se describieron trabajadores expuestos al polvo de mezcla de aluminio-oxido y cobre, concluyendo que puesto que el cobre frecuentemente está mezclado con otros metales como cadmio, zinc, estaño, arsénico, plata es difícil determinar que el cobre sea el causante de la Fiebre de los Metales o el Síndrome parecido a la Fiebre por Metales. Dada la variabilidad de patrones ocupacionales, la extensa utilización de cobre y su mezcla con otros metales así como falta de monitoreo de exposición es difícil afirmar que cobre tiene relación directa como causante de Fiebre de los Metales y Síndrome semejante a la Fiebre por Metales.

Por otra parte, en los estudios de Bruning T et al. Enterline PP et al. Rouling C et al., Chen R et al., ${ }^{18,20,24,23}$ el tabaco podría ser un factor de confusión. Aunque observamos que el grupo de trabajo de Seidler A et al. (2012) ${ }^{10}$ en su estudio a trabajadores de dos minas de cobre de la República Democrática Alemana expuestos a DNT fueron capaces de controlar este sesgo y demostraron que el aumento de incidencia del cáncer de pulmón ( $\mathrm{SIR}=1,29 ; 1,13$ a 1,46) era independiente del hábito tabáquico. Así mismo demostraron que no existía un aumento de la incidencia de cáncer de riñón (SIR = 1,01, IC del 95\%: 0,79 a 1,27) o del cáncer de vejiga ( $\mathrm{SIR}=1,04$, IC del 95\%: 0,82 a 1,30).

Existe escasa evidencia sobre las enfermedades relacionadas con la industria del reciclaje de cobre, lo que deja este campo de la investigación abierto para seguir con la búsqueda de nuevas evidencias.

A pesar de los grandes esfuerzos que han desarrollado las diversas instituciones como por ejemplo la OIT con sus recomendaciones para la Seguridad y Salud en Minas a Cielo Abierto en $1991^{4}$, el INSHT que a través de su enciclopedia de salud y seguridad en el trabajo (18) nos aporta información, debemos seguir fortaleciendo la investigación, fomentar programas de prevención y su adecuado cumplimiento. Ejemplo de ello, lo 
demuestra el trabajo realizado por Thomas CA, et al. (2009) ${ }^{27}$ sobre la evaluación de un programa de prevención implantado en una Industria del Cobre/Berilio en EEUU entre el año 2000 y 2007, donde se incluyeron en las instalaciones los controles de ingeniería específicos diseñados para reducir las exposiciones respiratorias, así como el énfasis en la reducción de la contaminación de la ropa y de la piel y la migración de polvo, mejorar el orden y la limpieza del lugar de trabajo, y la formación y participación de los trabajadores obteniendo como resultado una disminución a la sensibilización del berilio.

Este mapa muestra la situación actual de la distribución de los investigadores por millón de habitantes (Figura 2).

Figura 2. Número de Investigadores por millón de habitantes en el mundo ${ }^{19}$

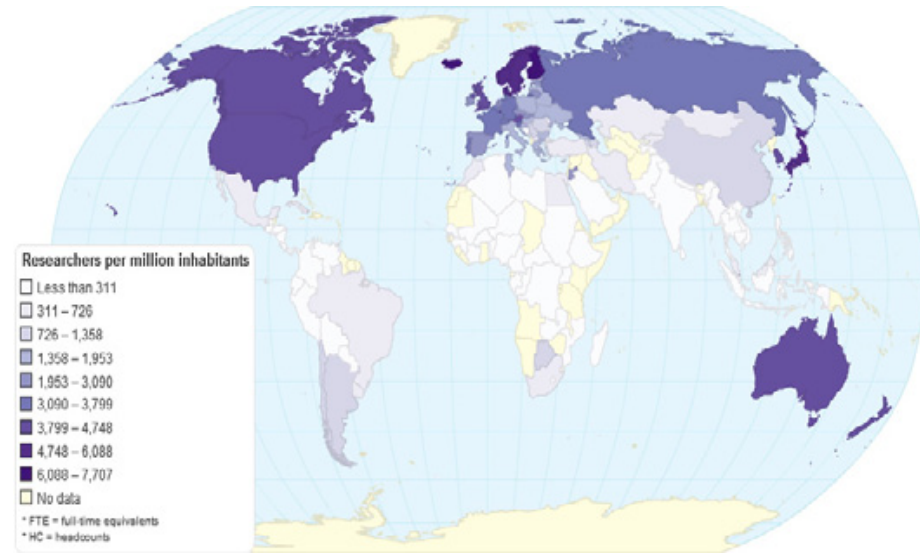

Lamentablemente observamos que en los países de América Latina existen muy pocos investigadores, lo cual nos limita a obtener estadísticas reales, ni suficiente evidencia científica sobre este tema, que nos permita conocer de forma global que enfermedades profesionales son las que más se han relacionado con la exposición laboral en los trabajadores de la industria del Cobre de este continente, que es responsable de más del 50\% de la producción mundial de Cobre y donde una gran cantidad de trabajadores se encuentran implicados.

\section{CONCLUSIONES}

El Cobre al ser un elemento fundamental es utilizado globalmente en las industrias energéticas. Su combinación con otros elementos le permite estar presente en todos los avances que continuamente se desarrollan. Su introducción en la elaboración de nuevos compuestos permite que se mantenga el mismo patrón de enfermedades halladas desde que los primeros investigadores estudiaran sobre este tema.

Las principales enfermedades asociadas a la exposición laboral de trabajadores de la industria del cobre no parecen ser debidas a la exposición directa de los trabajadores al cobre, sino a otros elementos utilizados en la industria, así como el medio ambiente y las condiciones de trabajo.

Se destaca en primer lugar el cáncer de pulmón y vías respiratorias, enfermedades respiratorias crónicas como la beriliosis y silicosis siendo el sector de la minería es el más afectado por cáncer al igual el de manufactura y fundición con enfermedades respiratorias crónicas en segundo lugar.

La toxicidad por $\mathrm{Cu}$ se debe principalmente al contacto directo con sales de Cu y sus principales vías de exposición son la ingesta y la inhalatoria, lo cual es muy raro.

La evidencia demuestra que existe una correlación directa entre los niveles elevados de $\mathrm{Cu}$ en sangre y la aparición de síntomas y enfermedades respiratorias crónicas. 
Actualmente existe escasa evidencia científica que demuestre las principales enfermedades que se generan en los trabajadores del sector de reciclado de cobre.

Consideramos que las medidas preventivas que se deben desarrollar en la industria del cobre deben estar diseñadas de acuerdo a las necesidades reales de los trabajadores e ir actualizándose continuamente adaptadas a los continuos cambios que sufre la industria en la actualidad; teniendo siempre como objetivo principal preservar la salud de los trabajadores que son el motor más importante de una sociedad. Es necesario mantener condiciones de trabajo favorables y evitar la contaminación del medio ambiente que nos rodea.

\section{BIBLIOGRAFÍA}

1. Group's SME. http://www.prweb.com. [Online]. Charlottesville; 2013 [cited 2013 November 30 . Disponible en: HYPERLINK "http://www.prweb.com/releases/2013/7/prweb10947479.htm» http://www.prweb.com/ releases/2013/7/prweb10947479.htm.

2. Secretaría de Estado de Seguridad Social. Las Enfermedades Profesionales desde la Perspectiva de la Seguridad Social. Madrid: Seguridad Social; 2007.

3. International Copper Study Group. http://www.icsg.org. [Online].; 2013 [cited 2014 January 21. Disponible en: HYPERLINK «http://www.icsg.org/index.php/component/jdownloads/finish/170/1188» http://www. icsg.org/index.php/component/jdownloads/finish/170/1188.

4. OIT. Organización Internacional del trabajo. Repertorio de recomendaciones prácticas sobre la seguridad y la salud en las industrias de los metales no ferrosos. Programa de actividades sectoriales. Reunión de expertos sobre la seguridad y la salud en las industrias de los metales no ferrosos; 2001.

5. Farreras de la Fuente A, Antolín García MT, García Arroyo MI. Silicosis. En Guía para la determinación de la Incapacidad Laboral en las Enfermedades Pulmonares. Madrid: Instituto Nacional de Medicina y Seguridad del Trabajo; 2000. p. 191-194.

6. Steenland K, Stayner L. Silica, asbestos, man-made mineral fibres, and cancer. Cancer Causes Control; 8(1997): p. 491-503.

7. Xaubet Mir A, Morrell Brotad F, Ancochea Bermudez J. Enfermedades Pulmonares de origen Ocupacional. En Farreras R. Medicina Interna. Barcelona: Elsevier; 2012. p. 694-698.

8. Cohen SR. A review of the Health Hazards from Copper Exposure. Journal of Occupational Medicine. 1974 September; 16(9): p. 621-24.

9. Lightfoot NE, Berriault CJ. Mortality and Cancer Incidence in a Copper-Zinc Cohort. Workplace Health $\mathcal{E}$ Safety. 2012; 60(5).

10. Seidler A, Brüning T, Taeger D, Möhener M, Gawrych K, Bergmann A, et al. Cancer incidence among workers occupationally exposed to dinitrotoluene in the copper mining industry. Int Arch Occup Environ Health. 2012 Dec.

11. Gasenzer ER, Neugebauer EA. Contact allergies in musicians. Dtsch Med Wochenschr. 2012 December;: p. 2715-21.

12. Abakay A, Gokalp, Abakay, Evliyaoglu, Sezgi, Palanci Y, et al. Relationships Between Respiratory Function Disorders and Serum Copper Levels in Copper Mineworkers. Biol Trace Elem Res. 2012; 145: p. 151-157.

13. Eren Dabli C, Cetin Tanrikulu C, Koksal N, Abakay A, Emin Gelen M, Demirpolat G, et al. Interstitial Lung Disease in Coppersmiths in High Serum Copper Levels. Biol Trace Elem Res. 2010; 137: p. 63-68.

14. Schuler CR, Kent MS, Deubner DC, Berakis MT, McCawley M, Henneberger PK, et al. Process-Related Risk of Beryllium Sensitization And Disease in a Copper-Beryllium Allow Facility. American Journal of Industrial Medicine. 2005; 47: p. 195-205.

15. Paredes Suárez C, Fernández-Redondo V, Toribio J. Bingo-hall worker's occupational coper contact dermatitis from coins. Contact Dermatitis. 2002 September; 47(2): p. 182.

16. Tarlo SM, Rhee K, Powell E, Amer E, Newman L, Liss G, et al. Marked Tachypnea in Siblings with Chronic Beryllium Disease due to Copper Beryllium Alloy. Chest. 2001 February; 119(2): p. 647-50.

17. Lubin JH, Pottern LM, Stone BJ, Fraumeni JF. Respiratory Cancer in a Cohort of Copper Smelter Workers: Results from More Than 50 Years of Follow-up. Am J Ind Med. 2000; 151(6). 
18. Bruning T, Chronz C, Thier R, Havelka J, Ko Y, Hermann M. Occurrence of Urinary Tract Tumors in Miners Highly Exposed to Dinitrotoluene. Journal of Occupational \& Environmental Medicine. 1999 March; 41(3): p. 144-49.

19. Jayawardana PL, de Alwis WR, Fernando MA. Ventilatory function in brass workers of Gadaladeniya, Sri Lanka. Occup. Med. 1997; 47(7): p. 411-15.

20. Enterline PP, Day R, Marsh GM. Cancers related to exposure to arsenic at a copper. Occupational and Environmental Medicine. 1995; 52: p. 28-32.

21. Anttila A, Pukkala E, Rantanen T, Karjalainen S. Update of cancer incidence among workers at a copper/ nickel smelter and nickel refinery. Int Arch Occup Environ Health. 1995 June; 71(4): p. 245-250.

22. Sorahan T, Lister A, Gilthorpe MS, Harrington JM. Mortality of copper cadmium alloy workwrs with special reference to lung cancer and non malignant diseases of the respiratory system, 1946-1992. Occup Environ Med. 1995; 52: p. 802-814.

23. Chen R, Wei L, Chen RL. Lung cancer mortality update and prevalence of smoking among copper miners and smelters. Scand J Work Environ Health. 1995; 21(6): p. 513-16.

24. Rouling C, Li W, Huaming H. Mortality from lung cancer among copper miners. British Journal of Industrial Medicine. 1993; 50: p. 505-9.

25. Borak J, Cohen H, Hethmon TA. Copper Exposure and Metal Fume Fever: Lack of Evidence for a Causal Relationship. AIHAJ. 2000;(61): p. 632-36.

26. Instituto Nacional de Seguridad e Higiene en el Trabajo. Disponible en: www.insht.es/InshtWeb/ Contenidos/Documentacion/./tomo2/63.pdf. [Online].; 2011.

27. Thomas CA, Bailey RL, Kent ML, Deubner DC, Kreiss K, Shuler CR. Efficacy of a Program to Prevent Beryllium Sensitization Among New Employees at a Copper-Beryllium Alloy Processing Facility. Public Health Reports. 2009; 124: p. 112-124.

28. ChartsBin.com. [Online]; 2011 [Citado enero 6 2014. Disponible en HYPERLINK «http://chartsbin.com/ view/1124” http://chartsbin.com/view/1124.

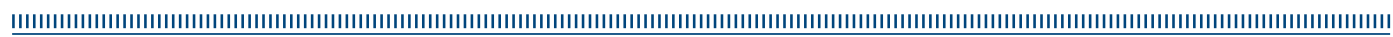

